DOI: https://doi.org/10.35699/2237-5864.2018.2478

\title{
A LEITURA NAS PRÁTICAS DE LETRAMENTO ACADÊMICO: ESTRATÉGIAS DE ANÁLISE E COMPREENSÃO
}

Marcela Tavares de Mello ${ }^{1}$

\section{RESUMO}

O presente trabalho tem por objetivo discutir e analisar as especificidades do ensino e da aprendizagem da leitura na esfera acadêmica, bem como apresentar algumas estratégias de ensino de leitura que podem ser utilizadas nesse contexto. Trata-se de uma análise exploratória de estudos que se debruçaram sobre a temática da leitura, sobretudo da leitura de textos acadêmicos. No conjunto analisado, destacam-se aspectos sobre os textos que circulam na academia, específicos dessa esfera, cujos termos próprios surgem como obstáculos aos graduandos para compreender e dialogar com as ideias ali presentes, e sobre como cabe ao professor, como mediador da leitura, auxiliar os graduandos, apresentando estratégias específicas que possibilitem direcionar a compreensão das leituras. Logo, percebese a necessidade de refletir sobre o processo de formação do leitor na graduação, tendo em vista que a inserção dos estudantes na prática social e discursiva do contexto acadêmico é fundamental para a permanência qualificada destes no Ensino Superior, o que colabora para a formação de sujeitos críticos e reflexivos.

Palavras-chave: Ensino Superior. Estratégias de leitura. Ensino-aprendizagem.

\footnotetext{
${ }^{1}$ Faculdade Santo Antônio de Pádua (FASAP), Santo Antônio de Pádua, RJ, Brasil.
} 


\title{
TEACHING AND LEARNING OF READING IN THE ACADEMIC SPHERE
}

Marcela Tavares de Mello

\begin{abstract}
This work aims to discuss and analyse the specificities of teaching and learning of reading in the academic sphere, as well as to present a few strategies of teaching reading. In the analyzed set, it was possible to highlight that the texts that circulate in the academy are, in general, speficic of this sphere and present their own terms of a determined area, in which the graduating students' challenges come up in comprehending and conversating with the ideas present there. It is also noticed, bearing in mind, that reading can be taught, and it is up to the teacher, as a mediator of reading, to help graduating students, presenting specific strategies that make the comprehension of these texts possible, and thus, collaborating with the formation of reflexive and critical individuals.
\end{abstract}

Keywords: Higher Education. Reading strategies. Teaching-learning. 


\section{INTRODUÇÃO}

O presente trabalho tem por objetivo discutir e analisar as especificidades do ensino e da aprendizagem da leitura na esfera acadêmica, bem como apresentar algumas estratégias de ensino de leitura que podem ser utilizadas nesse contexto. Para isso, apresento algumas reflexões a partir de análises de pesquisas sobre a leitura, sobretudo a leitura de textos acadêmicos que têm uma abordagem orientada pelo modelo interacionista, ou seja, que compreende a linguagem como forma ou processo de interação (KLEIMAN, 1989a, 1995).

Refiro-me, principalmente, aos trabalhos desenvolvidos por Carvalho e Mello (s. d.), Machado, Lousada e Abreu-Tardelli (2007) e Kleiman (1989a), que nos apresentam discussões significativas sobre o ensino e a aprendizagem da leitura no contexto acadêmico. Conforme defendido pelas pesquisadoras, podemos considerar que o sentido do texto é aquele construído pelo leitor por meio dos diálogos que este estabelece com o texto.

Para refletir acerca dessas questões, inicialmente, apresento uma breve discussão acerca das definições de leitura e sobre as ações desenvolvidas no ato de ler. Em seguida, aponto algumas especificidades da leitura, considerando o contexto acadêmico. Finalmente, trago algumas estratégias de ensino embasadas nas experiências das pesquisadoras Carvalho e Mello (s. d.) e nos pressupostos de Machado, Lousada e Abreu-Tardelli (2007), no que tange à leitura de textos acadêmicos.

\section{ESTUDOS SOBRE A LEITURA}

Entende-se por leitura o processo de interlocução, mediado pelo texto, entre o leitor e o autor. Em outras palavras, tem-se a leitura como relação ou interação entre o leitor e a informação, como construção de sentido, como aponta Solé $(1998,2018)$. Nesse sentido, a leitura desempenha um papel essencial no processo de constituição do sujeito, tendo em vista que ela pode ser considerada uma das bases para a formação humana e para a construção de uma sociedade mais justa (PETIT, 2008).

Existem vários modelos teóricos que explicam o que acontece com o leitor no ato de ler (KATO, 1999). Por esse prisma, destacam-se as orientações de leitura baseadas no modelo interacionista de Angela Kleiman (1989a, 1989b, 1995) segundo o qual a compreensão dos sentidos do texto ocorre graças à interação entre sistemas cognitivos e linguísticos, isto 
é, por meio da interação entre diversos níveis de conhecimento do sujeito leitor, desde o conhecimento gráfico até o conhecimento do mundo (CARVALHO, 2004). Nas palavras de Kleiman:

\begin{abstract}
A compreensão de um texto é um processo que se caracteriza pela utilização de conhecimento prévio: o leitor utiliza na leitura o que ele já sabe, o conhecimento adquirido ao longo da vida. É mediante a interação de diversos níveis de conhecimento, como o conhecimento linguístico, o textual, o conhecimento do mundo, que o leitor consegue construir o sentido do texto. E porque o leitor justamente utiliza diversos níveis de conhecimento que interagem entre si, a leitura é considerada um processo interativo. Pode-se dizer com segurança que sem o engajamento do conhecimento prévio do leitor não haverá compreensão (KLEIMAN, 1989b, p.13).
\end{abstract}

Isso significa que o ato da leitura não consiste apenas em decodificar as palavras e/ou perceber apenas o que está escrito. $O$ ato de ler significa integrar o que os textos trazem com o conhecimento de mundo do leitor, tornando-se necessário, para isso, discutir e dialogar com seu autor, como lembrou Freire (2001). Dessa maneira, pode-se afirmar que ao se ler é possível rejeitar ou confirmar as informações expostas no texto.

Esses pressupostos vão ao encontro das palavras de Marcuschi (2008, p. 228), quando este enfatiza que "ler é um ato de produção e apropriação de sentido que nunca é definitivo e completo [...] não é um ato de simples extração de conteúdos ou identificação de sentidos". Para o autor, a compreensão está associada a aspectos cognitivos internalizados ao longo da nossa vida social, no coletivo, e não aos aspectos individuais e únicos. Diante disso, a leitura deve ser promovida "como uma ação solidária e coletiva no seio da sociedade" (2008, p. 232).

Diante dessa análise, podemos concluir que a postura assumida pelo leitor durante a leitura interfere diretamente na compreensão do texto, podendo aquele ser um sujeito da leitura ou um objeto da leitura. Os fatores que distinguem esses dois tipos de leitor foram apontados por Luckesi et al. (2005), quando evidenciaram que o leitor-objeto não se compromete com a construção de novos conhecimentos, seu objetivo é apenas armazenar as informações presentes nos textos e reproduzi-las quando necessário. Em outras palavras, não critica, não investiga nem dialoga com o texto. Em contrapartida, o leitor-sujeito é aquele que desenvolve uma postura crítica e comunicativa com o texto, sendo capaz de produzir variados sentidos ao texto e, até mesmo, tornar-se um leitor-autor ao expressar novas interpretações da realidade. 
Essa definição de leitor-sujeito encontra eco no conceito de leitor maduro, proposto por Geraldi. O autor afirma que o leitor maduro é "aquele para quem cada nova leitura descola e altera o significado de tudo que ele já leu, tornando mais profunda sua compreensão dos livros, das gentes e da vida" (2012, p. 92).

Em decorrência da postura adotada pelo leitor, é possível desenvolver, então, uma compreensão passiva ou uma compreensão ativa do texto analisado. Nesta o leitor dialoga com o texto, ou seja, acontece uma negociação de sentido entre leitor e informação, enquanto naquela o leitor apenas recebe informação socializada no texto como pronta, única (MACHADO; LOUSADA; ABREU-TARDELLI, 2007).

Na próxima seção, para aprofundar o assunto, busco responder ao seguinte questionamento: como formar um leitor maduro ou, nas palavras de Luckesi et al. (2005), um leitor-sujeito?

\section{ALGUMAS ESTRATÉGIAS DE ENSINO}

"O ensino das estratégias de leitura ajuda o estudante a aplicar seu conhecimento prévio, a realizar inferências pra interpretar o texto e a identificar e esclarecer o que não entende" (Isabel Solé).

Assim como Pozo (1996), neste texto, compreendem-se por estratégias os métodos utilizados para alcançar o objetivo proposto, no caso em estudo, a compreensão textual. Ademais, podem ser elucidadas como procedimentos processuais que possibilitam a aquisição, o armazenamento e a utilização eficaz das informações. Em síntese, as estratégias são elementos que facilitam os processos de compreensão e apreensão das ideias compartilhadas nos textos.

Tendo em vista que nas atividades de leitura o propósito é a compreensão ativa dos textos, apresento, a seguir, com base em pesquisadores da área, algumas estratégias que podem ser ensinadas e mobilizadas no processo de leitura.

Sabemos que a leitura é orientada por diversos objetivos, sendo assim, a princípio, torna-se proveitoso que o professor aponte, de forma clara, o objetivo da leitura do texto proposto aos alunos. Destacam-se como objetivos: buscar informações gerais ou específicas, estudar, seguir instruções, ler por ler. Percebe-se que os objetivos são inúmeros e, como afirma Solé, "levam a diferentes posturas diante da matéria escrita" (2018, p. 4). 
Nesse sentido, Angela Kleiman (1989b) chama atenção para a capacidade de estabelecer objetivos para a leitura como uma estratégia metacognitiva de controle e regulamento do próprio conhecimento. A leitura errática, desmotivada, para dar conta de uma tarefa escolar indeterminada, em geral, não produz aprendizagem.

Além de estabelecer o objetivo da leitura, antes de iniciá-la, partir de uma indagação ou de uma hipótese sobre o conteúdo provável do texto - a partir do título e subtítulos, por exemplo - é uma estratégia que também facilita a compreensão. Segundo Kleiman (1989b), as hipóteses iniciais do leitor sobre o que vai encontrar no corpo do texto fazem com que certos aspectos do processamento, essenciais à compreensão, tornem-se possíveis, tais como o reconhecimento global e instantâneo de palavras e frases relacionadas ao tópico, bem como a inferência sobre palavras não percebidas durante a "sacada", ou seja, o movimento que fazem os olhos do leitor para ler um grupo de palavras de cada vez.

Com base em minha experiência como professora e pesquisadora, percebo ainda que quando, antes de propor a leitura, mostro de que forma o conteúdo tratado no texto interfere na vida acadêmica e profissional do aluno e/ou esclareço de que forma este pode incorporar determinado conteúdo para transformar seu próprio conhecimento e as possíveis conexões que podem ser feitas com outras áreas, os estudantes se sentem motivados para a leitura.

No decorrer da leitura, o leitor deve lançar mão de seus conhecimentos prévios, prever, diagnosticar suas dúvidas e obstáculos encontrados no texto e, principalmente, controlar e verificar sua compreensão. Segundo Isabel Solé,

As estratégias realizadas antes, durante e depois da leitura ajudam o estudante a utilizar conhecimento prévio, a realizar inferências para interpretar o texto, a identificar as coisas que não entende e esclarecêlas para que possa retrabalhar a informação encontrada por meio de sublinhados e anotações num pequeno resumo, por exemplo (2018, p. 3).

Nos encaminhamentos adotados em minha prática, costumo dizer aos estudantes que um texto que consideram difícil possivelmente se tornará mais fácil se houver: a) consulta a outros textos (introdutórios, explicativos ou de comentários) que auxiliam o leitor a percorrer os meandros de significados; b) diálogo com o autor sob a forma de perguntas que o leitor faz à medida que lê; c) anotações breves no próprio texto; d) marcas que sublinham passagens significativas. Destaco ainda que ler o texto mais de uma vez geralmente é necessário, mas 
é preciso que cada leitura invoque novas perguntas ao autor. Certas palavras desconhecidas podem ser inferidas pelo contexto, outras serão objeto de consulta.

Além dessas estratégias de leitura, outro aspecto que merece destaque diz respeito à conexão entre leitura e escrita como forma de aprendizado. Solé (1998) aponta que a hibridização entre a leitura e a escrita impacta de forma relevante a aprendizagem dos leitores quando se tem como objetivo de leitura a aprendizagem. Em relação a esse aspecto, apresentam-se como estratégias: a produção de resumo, desmembramento do texto, produção de diários de leitura, esquemas ou gráficos utilizando palavras-chave. Machado, Lousada e AbreuTardelli (2007), nesse sentido, partem do princípio - com o qual eu concordo e vejo resultados significativos em meus trabalhos - de que a escrita é uma forma de o leitor se apropriar do que lê.

Como tratamos da conexão entre leitura e escrita como forma de aprendizado, abro aqui um parêntese para enfatizar a relevância dos estudos dos gêneros textuais no processo de ensino e aprendizagem não só da escrita, mas também da leitura. Os textos, os gêneros textuais, possuem características, como aponta Bakhtin (2003), relativamente estáveis. Assim, conhecer essas características (conteúdo temático, plano composicional e estilo) e entender o funcionamento dos gêneros textuais auxilia, de forma significativa, o processo de compreensão textual.

Ao analisar as definições e as estratégias expostas no que tange à leitura, percebe-se que todas sinalizam para aspectos que se coadunam, tais como: a) ler implica (re)construir significados; b) é preciso que o leitor assuma uma postura ativa, crítica e reflexiva diante da leitura; c) ler implica fazer inferências, fazer referência com a realidade, criar hipóteses; d) a leitura compreende um diálogo entre o leitor e o texto. No item a seguir, discuto questões que envolvem o ensino e a aprendizagem da leitura na esfera acadêmica.

\section{LEITURA NA ESFERA ACADÊMICA}

Lamentavelmente, várias pesquisas (MELLO, 2014; RESENDE, 2010; SANTOS, 2005) apontam que na Educação Básica a realidade do trabalho realizado pelos professores é diferente das propostas apresentadas na seção anterior. Os exercícios de compreensão ainda contemplam apenas a decodificação dos textos, deixando de lado a interpelação crítica. Em outras palavras, os professores não incentivam o diálogo entre o leitor e o autor do texto. 
Refletindo sobre o ensino da leitura na esfera acadêmica, além dessas questões oriundas da Educação Básica que comprometem o processo de compreensão textual dos estudantes, dois aspectos merecem atenção.

O primeiro aspecto se refere ao fato de que o público-alvo dos textos científicos, comumente, são especialistas do assunto, que trazem consigo conhecimentos prévios sobre determinadas questões que auxiliam na compreensão dos textos. Conhecimentos que, em geral, ainda não foram desenvolvidos pelos graduandos. Sobre esse aspecto, trago a assertiva da pesquisadora Solé (2018, p. 2) que diz "se eu, leitora experiente, leio um texto filosófico, provavelmente terei dificuldades, pois não estou familiariza com esse material".

O segundo aspecto se relaciona ao fato de que, quando ingressam no ensino superior, os estudantes se deparam com gêneros discursivos próprios da esfera acadêmica, geralmente diversos daqueles que faziam parte de outros níveis de escolarização, bem como de outros espaços pelos quais circularam antes de ingressar na academia. Em consequência, como adverte Severino,

[...] habituados à abordagem de textos literários, os estudantes, ao se defrontarem com textos científicos ou filosóficos, encontram dificuldade logo julgadas insuperáveis e que reforçam uma atitude de desânimo e de desencanto, geralmente acompanhada de um juízo de valor depreciativo em relação ao pensamento teórico (2007, p. 49).

A prática de ler, na universidade, outros gêneros diferentes daqueles com que costumavam estar familiarizados modifica os hábitos e as estratégias dos leitores e abre espaço para novas aprendizagens. Fica evidente, a partir do cenário exposto, que a fim de que tenham um bom desempenho no tocante à leitura de textos acadêmicos, os graduandos precisam não só conhecer os termos técnicos específicos das disciplinas, mas também as características dos gêneros acadêmicos em que tais textos se concretizam, consideradas as especificidades da esfera acadêmica.

As reflexões expostas anteriormente vão ao encontro dos estudos realizados por Lea e Street (2014), Gee (1999), Lillis (1999), e Russel, em entrevista dada a Ramos e Espeiorin (2009), que comprovam que os desafios encontrados e vivenciados pelos discentes devem-se ao fato de que as convenções que regem o contexto acadêmico são distintas daquelas que orientam o Ensino Médio, ou seja, textos, maneiras de agir e interagir específicos daquele meio. Sendo assim, pode-se afirmar que, ainda que esses discentes sejam competentes leitores e 
produtores de textos, o desenvolvimento dessas novas linguagens não é processado de forma automática. Isso significa que as barreiras relacionadas à compreensão e à produção textual tendem a ser enfrentadas por qualquer discente que ingresse no Ensino Superior.

Além dessas ocorrências, faz-se necessário salientar que a universidade precisa formar leitores que desenvolvam uma postura ativa durante a leitura e que o ensino de boa qualidade não apenas informa sobre assuntos específicos, mas oferece leituras que geram curiosidade, ideias e conceitos que alargam o conhecimento de mundo dos estudantes. Para que isso aconteça, como destaca Vian,

é preciso promover a inserção mais eficiente e de forma menos traumática do aluno na comunidade discursiva em que está ingressando, suscitando, assim, sua familiarização com suas futuras experiências acadêmicas, que, pode-se dizer, são determinadas, em parte, pelos gêneros discursivos (2011, p. 75).

O estudo da situação exposta permite pensar que seria desejável que nós, professores, desenvolvêssemos uma consciência de nosso papel de produtores de leitura: mudam os leitores, mudam os suportes de textos, mas a leitura para fins de estudo continua a ser um exercício intelectual complexo e, o que é melhor, passível de ser ensinado.

Assim, o professor atuaria como um mediador, contemplando, entre outras funções, o papel de: a) aproximar o leitor dos textos - construir pontes entre o leitor e o texto - contaminando as outras pessoas com a paixão pela leitura; b) apoiar as escolhas de livros; c) ajudar o leitor a superar dificuldades. Além disso, caberia ao mediador (professor) mobilizar ações que visassem conscientizar o aluno de que a leitura importante é aquela que mostra ao indivíduo que é possível "sair do caminho que tinham traçado para ele, escolher sua própria estrada, [...] ter direito a tomar decisões [...], em vez de sempre se submeter aos outros" (PETIT, 2008, p. 100).

Todavia, é possível perceber que, de modo geral, a leitura é conduzida na escola como se todos os alunos, por terem sido alfabetizados, fossem capazes de abordar diferentes estruturas textuais e compreender textos complexos. Em outras palavras, os docentes naturalizam e consideram que os estudantes já deveriam saber e estar preparados para as práticas de leitura e escrita demandadas. Percebe-se, ainda, o descaso por parte de alguns docentes que, mesmo tendo consciência de que o ensino da leitura e da escrita é um processo contínuo e situado, 
não se preocupam e/ou não se sentem responsáveis por auxiliar o estudante a se inserir no contexto acadêmico, no que tange aos usos da linguagem.

Ao analisar o exposto, destaca-se que, para que os discentes possam transpor os obstáculos relacionados à leitura de textos acadêmicos e consigam obter sucesso na formação, fazse necessário que os professores universitários os motivem e os auxiliem, apresentando estratégias específicas que possibilitem direcionar a compreensão desses textos e, assim, colaborar para a formação de sujeitos críticos e reflexivos.

\section{PRÁTICAS DE ENSINO-APRENDIZAGEM DA LEITURA NO CONTEXTO ACADÊMICO}

"Tornar-se leitor proficiente, depende de um processo de ensinoaprendizagem sistemático" (Isabel Solé).

Levando em conta que as estratégias de leitura podem ser ensinadas, nesta última seção que tem um caráter propositivo - apresento dois encaminhamentos pedagógicos, sendo o primeiro baseado nas experiências das pesquisadoras Carvalho e Mello (s. d.) e o segundo apoiado nos pressupostos de Machado, Lousada e Abreu-Tardelli (2007).

No que diz respeito à leitura, sabe-se que na graduação grande parte dos textos socializados e analisados se concretiza no gênero discursivo artigo científico. Sendo assim, o gênero artigo acaba sendo utilizado como o principal meio do ensino e da aprendizagem. Considerando a incidência do referido gênero, na prática proposta por Carvalho e Mello (s. d.), as docentes, a fim de auxiliar os discentes tanto no processo de compreensão quanto no processo de produção de artigos científicos, levam os alunos a refletir sobre as características e a forma com que o texto é elaborado.

Geralmente não faz parte dos hábitos de estudo dos graduandos analisar os textos quanto à estrutura, quanto à maneira pela qual foram construídos. Por esse motivo, nas oficinas de produção e leitura de textos oferecidas, as pesquisadoras costumam trabalhar a leitura de alguns artigos acadêmicos, analisando-os, desconstruindo os textos em suas partes principais e mostrando como o autor trabalha com a língua escrita para expor, destacar, comparar, entrelaçar ideias; que palavras e expressões utiliza para unir, costurar os parágrafos; que recursos usa para atrair a atenção do leitor para aspectos importantes do texto; e, finalmente, 
como utiliza o arcabouço teórico-metodológico para analisar os resultados e fundamentar suas conclusões.

Além disso, na intenção de refletir sobre as informações tratadas no texto, indagam, por exemplo, sobre as bases teóricas em que se apoia o autor, quais os autores com quem este dialoga, qual o argumento ou ponto de vista que está defendendo, quais as evidências apresentadas para sustentar a argumentação e a que conclusões chegou. Para as autoras, esse procedimento auxilia o aluno a perceber que fazer a leitura orientada para o alcance de determinados objetivos pode levá-lo a compreender melhor o texto. Entretanto, ainda assim, as pesquisadoras afirmam que é comum que os alunos tenham dificuldades para enfrentar a leitura de autores complexos.

A respeito da persistência dos obstáculos vivenciados pelos graduandos, parece-me oportuno trazer à tona alguns dados da pesquisa que realizei no doutoramento. No referido estudo-que teve como objetivo analisar as ações que promovem o letramento acadêmico, desenvolvidas em uma universidade pública, nas aulas observadas em que foram utilizados textos de caráter científico -, uma das professoras, sujeito da pesquisa, adotou como estratégia a leitura coletiva por meio de rodas de leitura. Na ocasião, foi possível perceber, a partir dos apontamentos realizados pelos estudantes durante a roda de leitura, que os graduandos se sentiam autônomos e inseridos naquele contexto, ademais interagiam e relatavam suas experiências.

Em uma das observações, a docente, ao discorrer sobre a relação de poder estabelecida entre professores e alunos, enfatizou que:

A roda é a única forma que eu conheço que a gente pode olhar pro outro. Se todos estão em fileira, eu olho todos, mas ninguém está olhando para todo mundo. E tem coisas que a gente aprende com o colega, não é com professor. Primeiro a roda ensina uma coisa que é muito importante: que o outro é legítimo. Se todo mundo olha apenas para o professor, o que a gente está querendo dizer silenciosamente é que só o professor é legítimo. Agora, quando eu estou em círculo, todo mundo é legítimo (MELLO, 2017, p. 67).

Do ponto de vista da professora, a maior dificuldade do graduando era encontrar-se como "sujeito-enunciador", por esse motivo, buscava em suas aulas algo que despertasse o pensar, o falar, o enunciar dos estudantes. Ao considerar as observações e as interações que ocorreram durante a leitura, apontei como relevante a estratégia adotada pela professora para trabalhar a leitura acadêmica. Percebi que o simples fato das carteiras estarem dispostas 
em círculo era uma maneira de dar voz aos discentes e fazer com que eles compreendessem que os seus posicionamentos também eram legítimos. Pude verificar ainda que os discentes compreenderam que o sentido dos textos era construído a partir de diálogos estabelecidos entre o leitor, a informação e o autor.

O segundo encaminhamento apresentado, proposto pelas pesquisadoras Machado, Lousada e Abreu-Tardelli (2007), trata da produção do gênero discursivo diário de leitura como forma de ensino da leitura. As autoras definem diário de leitura como um texto - de caráter privado - elaborado por um leitor, no momento em que realiza a leitura, que tem como intuito estabelecer diálogos realizados com o texto analisado. Tendo em vista o caráter privado dos gêneros da natureza de um diário, as reflexões pessoais são realizadas e registradas de forma mais livre. Acerca das características linguísticas do texto, em geral, é utilizada a primeira pessoa do singular. Tendo em vista que não há um destinatário, ou seja, um receptor real, os diários quase não apresentam unidades na segunda pessoa.

Antes de pontuar o que se registra em um diário de leitura, é preciso esclarecer que as autoras sinalizam para o fato de o significado do texto não estar atrelado apenas ao conteúdo e ao autor, mas sim às representações e às conexões que cada leitor estabelece a partir de suas experiências. Por isso, pode-se dizer que a produção de um diário de leitura é uma significativa ferramenta para o desenvolvimento das capacidades de leitura, já que ali são pontuadas as impressões pessoais do leitor.

Considerando o objetivo do diário de leitura, a produção textual deve contemplar: a) reações e hipótese sobre o primeiro contato com o livro; b) reações aos aspectos visuais e aos títulos de matérias em meios impressos e digitais; c) reações aos títulos de artigos científicos de diferentes áreas; d) reações à bibliografia; e) levantamento do que é significativo para o leitor; f) registro das dificuldades de leitura e os procedimentos para sua solução; g) registro de reações diante do texto; h) registro das relações estabelecidas pelo leitor entre o texto e suas experiências pessoais e entre o texto e outros objetos culturais; i) registro das relações estabelecidas pelo leitor entre o texto e outros textos lidos.

Ao analisar a forma como o texto é preenchido, pode-se dizer que no diário são registrados aspectos considerados significativos para seu autor. Isso significa que predominam as impressões pessoais, tais como dificuldades de leitura, reações subjetivas, relações estabelecidas com outros textos e/ou com as vivências etc. Além disso, é possível verificar que 
tais registros contemplam tanto as primeiras reações apresentadas quando se inicia a leitura quanto as conexões estabelecidas no decorrer da leitura. Não há uma estrutura rígida.

Para fazer a transposição do gênero diário de leitura para fins de ensino e aprendizagem, Machado, Lousada e Abreu-Tardelli (2007) destacam que primeiramente se faz necessário esclarecer para o aluno o objetivo de sua produção. Em seguida, propõem que a tarefa global seja divida em pequenas tarefas. Como exemplo, o professor pode instruir o aluno a: expor suas dúvidas, posicionar-se diante do que lê, relacionar texto e experiências vividas etc. É preciso destacar que, embora as tarefas sejam divididas, não existe uma cronologia para desenvolver tais ações, uma vez que elas surgem e são realizadas de acordo com a experiência e a leitura realizada pelo graduando.

Nesta seção, procurei elucidar estratégias de leitura que podem ser trabalhadas não só com alunos da graduação, mas também com estudantes da Educação Básica. As propostas trazidas à tona apresentam características fundamentais para a formação de leitores (e escritores) críticos e reflexivos, capazes de relacionar os conhecimentos desenvolvidos na escola às experiências pessoais. Conforme defendem as autoras, é preciso criar espaços para ensinar a leitura em sala de aula, e o referido ensino compreende: "incentivar o aluno a se expressar, fazer avaliações sobre o que leem de forma justificada e pessoal, ou seja, criar espaços onde ele possa criticar os textos, apontar suas diferentes interpretações, suas dificuldades, e suas reações pessoais" (MACHADO; LOUSADA; ABREU-TARDELLI, 2007, p. 119).

As estratégias apresentadas para a leitura dos textos acadêmicos (consulta a outros textos, diálogo com o autor, marcas significativas, e produção escrita como forma de o leitor se apropriar daquilo que lê), embora possam parecer básicas para alguns docentes, podem ser problematizadas/inovadas para outros. Além disso, tais estratégias são de suma importância e contribuem, de fato, para a produção de sentido no ato de leitura de um texto de cunho acadêmico.

\section{CONSIDERAÇÕES FINAIS}

As análises expostas levam-me a fazer algumas considerações a partir das teorias que me têm auxiliado a pensar a leitura, sobretudo a leitura na esfera acadêmica. Com base nas informações dispostas, é possível afirmar que a leitura, como processo de interação, compreende um 
diálogo entre leitor e autor acerca das informações tratadas no texto, que se concretiza por meio de ações realizadas no processo de leitura.

Tendo em vista que tais ações podem ser ensinadas por meio do desenvolvimento de estratégias, evidencia-se o papel fundamental dos professores, intervindo e apresentado estratégias que auxiliem os discentes a compreender e dialogar com os textos presentes na academia.

Nas estratégias descritas, é possível verificar que todas as propostas visam a desenvolver uma leitura ativa, ou seja, fazer com que os alunos se tornem sujeitos da leitura, corroborando com a interação entre o leitor e o autor. Os teóricos demonstram também a possibilidade e a importância de orientar os graduandos a controlar, avaliar e refletir sobre o processo de aprendizagem durante a leitura. Assim, acredita-se que cada leitor interessado possa encontrar seu caminho e posteriormente internalizar as estratégias em suas práticas de leitura.

No que diz respeito à leitura na graduação, como assinalei, os obstáculos vivenciados pelos graduandos são acentuados, já que: a) em geral, na Educação Básica, a leitura ensinada compreende apenas exercícios de decodificação dos textos, assim alguns alunos chegam à graduação sem habilidade de interpretar textos e realizar uma leitura mais profunda; b) os gêneros discursivos que circulam na academia são próprios da esfera acadêmica, geralmente diversos daqueles que faziam parte de outros níveis de escolarização; c) os textos científicos têm como público-alvo especialistas do assunto que trazem consigo conhecimentos prévios sobre determinadas questões que auxiliam na compreensão dos textos.

As reflexões realizadas anteriormente ratificam a necessidade da criação de políticas de formação de leitores e a importância da conscientização do papel do professor como mediador do processo do ensino e da aprendizagem da leitura Sabe-se que a leitura é um dos aspectos essenciais para o desenvolvimento de qualquer indivíduo, sendo assim, faz-se necessário que escola e universidade formem leitores maduros, sujeitos da leitura.

A inserção de estudantes de graduação na prática social e discursiva do contexto acadêmico é fundamental para a permanência qualificada no âmbito acadêmico. Daí a necessidade de refletirmos sobre o processo de formação do leitor na graduação, considerando o professor como um mediador da produção de sentidos por meio da leitura. 


\section{REFERÊNCIAS}

BAKHTIN, Mikhail. Estética da criação verbal. 4. ed. Trad. P. Bezerra. São Paulo: Martins Fontes, 2003.

CARVALHO, Marlene. Trajetórias de leitura de estudantes de Pedagogia: avanços, aquisições, dificuldades. Educação e Contemporaneidade, Salvador, v. 13, n. 21, p. 61-75, jan./jun., 2004.

CARVALHO, Marcela; MELLO, Marcela. Quem ensina o mestrando a escrever? Programa de Pós-Graduação em Educação. Disciplina Práticas pedagógicas de produção de textos acadêmicos. [s. d.]. (Texto não publicado).

FREIRE, Paulo. A importância do ato de ler. 41. ed. São Paulo: Cortez, 2001.

GEE, Jean Paul. Social Linguistics and literacies: ideology in discourses. 2. ed. London; Philadelphia: The Farmer Press, 1999.

GERALDI, João Wanderley (Org.). O texto na sala de aula. São Paulo: Anglo, 2012.

KATO, Mary. No mundo da escrita. Uma perspectiva psicolinguística. 7. ed. São Paulo: Ática, 1999.

KLEIMAN, Angela Bustos. Leitura: ensino e pesquisa. Campinas: Pontes, 1989a.

KLEIMAN, Angela Bustos. Texto e leitor. Aspectos cognitivos da leitura. 2. ed. Campinas: Pontes, 1989b.

KLEIMAN, Angela Bustos. Os significados do letramento: uma nova perspectiva sobre a prática social da escrita. Campinas: Mercado das Letras, 1995.

LEA, Mary; STREET, Brian. O modelo de "letramentos acadêmicos": teoria e aplicações. Revista Filologia e Linguística Portuguesa, São Paulo, v. 16, n. 2, p. 477-493, jul./dez., 2014.

LILLIS, Thereza. Whose 'Common Sense'? Essayist literacy and the institutional practice of mystery. In: JONES, C.; TURNER, J.; STREET, B. (Org.). Students writing in the university: cultural and epistemological issues. Amsterdam: John Benjamins, 1999.

LUCKESI, Cipriano Carlos et al. Fazer universidade: uma proposta pedagógica. 14. ed. São Paulo: Cortez, 2005. 
MACHADO, Anna Rachel; LOUSADA, Eliane; ABREU-TARDELLI, Lília Santos Abreu. Trabalhos de pesquisa: diários de leitura para a revisão bibliográfica. São Paulo: Parábola, 2007. v. 1. (Coleção Leitura e produção de textos técnicos e acadêmicos).

MARCUSCHI, Luiz Antônio. Produção textual, análise de gêneros e compreensão. São Paulo: Cortez, 2008.

MELLO, Marcela Tavares de. Gêneros Textuais: teoria e prática numa escola municipal de Pirapetinga. 2014. 124 f. Dissertação (Mestrado em Educação) - Universidade Católica de Petrópolis, Petrópolis, 2014.

MELLO, Marcela Tavares de. Letramentos acadêmicos: teoria e prática. Curitiba: CRV, 2017.

PETIT, Michele. Os jovens e a leitura: uma nova perspectiva. Tradução de Celina Olga de Souza. São Paulo: Ed. 34, 2008.

POZO, Juan Ignácio. Estratégias de aprendizagem. In: MARCHESI, A.; COLL, C.; PALÁCIOS, J. (Org.). Desenvolvimento psicológico e educação: psicologia da educação. Tradução de Angélica Mello Alves. Porto Alegre: Artes Médicas, 1996. p. 176-197.

RAMOS, Flávia Brochetto; ESPEIORIN, Vania Marta. Letramento acadêmico: leitura e escrita na universidade - entrevista com David Russel. Conjectura, v. 14, n. 2, maio/ago., 2009.

RESENDE, Valéria Barbosa. Letramento escolar: eventos e apropriações de gêneros textuais por adolescentes. 2010. 194 f. Tese (Doutorado em Educação) - Faculdade de Educação, Universidade Federal de Minas Gerais, Belo Horizonte, 2010.

SANTOS, Aline Oliveira Moura. Um gênero é pouco, dois é bom, três nunca é demais: reflexões sobre o uso de textos e as estratégias de leitura na escola. 2005. $244 \mathrm{f}$. Dissertação (Mestrado em Educação) - Faculdade de Educação, Universidade Federal da Bahia, Salvador, 2005.

SEVERINO, Antônio Joaquim. Metodologia do trabalho científico. 23. ed. rev. e atual. São Paulo: Cortez, 2007.

SOLÉ, Isabel. Estratégias de leitura. Porto alegre: Artes médicas, 1998.

SOLÉ, Isabel. Para Isabel Solé, a leitura exige motivação, objetivos claros e estratégias. Entrevista concedida a Rodrigo Ratier. Revista Nova Escola, São Paulo, 7 mar. 2018. 
Disponível em: <https://novaescola.org.br/conteudo/304/para-isabel-sole-a-leituraexige-motivacao-objetivos-claros-e-estrategias>. Acesso em: 14 nov. 2018.

VIAN, Orlando. O artigo na família de gêneros acadêmicos: notas sobre aspectos tipológicos, topológicos e seu papel no ensino-aprendizagem de leitura. In: BARBARA, Leila; MOYANO, Estela (Org.). Textos e linguagem acadêmica. Campinas: Mercado das Letras, 2011.

\section{Marcela Tavares de Mello}

Doutora em Educação, atua como professora na Faculdade Santo Antônio de Pádua (FASAP), onde ministra disciplinas relacionadas à pesquisa e à orientação da leitura e da escrita no âmbito acadêmico. Além disso, integra os grupos de pesquisa Laboratório de Pesquisa em Infância, Imaginário e Subjetividades e Grupo de Estudos e Pesquisa em Leitura e Escrita Acadêmica.

marcelatdm@gmail.com 